\title{
TECHNOPARK INDUSTRIAL FURNITURE IN JEPARA WITH A TROPICAL ARCHITECTURE APPROACH TECHNOPARK INDUSTRI FURNITURE MEUBEL DI JEPARA DENGAN PENDEKATAN ARSITEKTUR TROPIS
}

\author{
Ferry Febriyanto $^{1)}$, Gatoet Wardianto ${ }^{2)}$, Carina Sarasati ${ }^{3)}$ \\ Program Studi Arsitektur, Fakultas Teknik, Universitas Pandanaran \\ ferryfebriyanto567@gmail.com \\ gatoetwardianto@yahoo.com \\ carinasarasati@unpand.ac.id
}

\begin{abstract}
Abstrak
Saat ini industri kreatif di Indonesia memiliki peran penting pada pertumbuhan ekonomi sehingga potensi tersebut harus bisa difasilitasi dengan baik, apabila penggunaan pusat kegiatan kreatif Indonesia ini bisa difasilitasi dengan baik maka Industri kreatif di Indonesia dapat berkarya tidak hanya di tingkat nasional namun bisa hingga tingkat internasional. Technopark yang berbasis industri kawasan terpadu ini menggabungkan dunia industry,perguruan tinggi,Pusat Riset,pelatihan,kewirausahaan,dan Pemerintah Pusat dalam satu lingkup. Lokasi yang di pilih untuk perencanaan dan perancangan Technopark adalah di jalan Jepara-Bangsri kota Jepara. Kriteria untuk perencanaan dan perancangan Technopark disekitar tapak sangat mendukung seperti fasilitas transportasi umum maupun industri furniture guna mendukung kegiatan industri. Tujuan perencanaan dan perancangan ini untuk menghasilkan konsep desain bangunan technopark yang memberikan solusi permasalahan dari segi arsitektur tropis sehingga mampu menjadi referensi bangunan industri yang berbasis teknologi di kota Jepara. Metode yang digunakan adalah dengan melakukan pendekatan dari sisi arsitektural seperti aspek konstektual,fungsional dan memperhatikan aspek perilaku serta mencantumkan icon simbol dan ciri khas rumah daerah jepara. Adanya Technopark industri furniture meubel di Jepara, selain menjadikan bangunan arsitektur yang indah,bangunan ini dapat menjadikan icon gedung pusat industri furniture utama di Jepara.

Kata Kunci : Technogi Park,Science Park,Arsitektur Tropis.
\end{abstract}

\begin{abstract}
Currently the creative industry in Indonesia has an important role in economic growth so that this potential must be facilitated properly, if the use of this center for creative activities in Indonesia can be facilitated properly, the creative industry in Indonesia can work not only at the national level but also at the international level. This integrated area industry-based Technopark combines the world of industry, universities, research centers, training, entrepreneurship, and the Central Government in one scope. The location chosen for planning and designing Technopark is on the Jepara-Bangsri road, Jepara city. The criteria for planning and designing Technopark around the site are very supportive such as public transportation facilities and the furniture industry to support industrial activities. The purpose of planning and designing is to produce a technopark building design concept that provides solutions to problems in terms of tropical architecture so that it can become a reference for technology-based industrial buildings in the city of Jepara. The method used is to take an architectural approach such as contextual, functional aspects and pay attention to behavioral aspects and include symbols and characteristics of houses in the Jepara area. The existence of the furniture industry Technopark in Jepara, apart from making a beautiful architectural building, this building can become an icon for the main furniture industry center building in Jepara. 579756

Keywords: Technogi Park,Science Park, tropical architecture
\end{abstract}




\section{PENDAHULUAN}

Teknopark atau Sciencepark sebuah fasilitas bangunan yang bekerjasama antara industry,pemerintah dan pendidikan/penelitian. Industri berbasis Technopark diharapkan mampu memberiksan solusi di bidang industri furniture industri khususnya di kota Jepara sesuai julukan sebagai pusat kota ukir Jawa Tengah. Industri furniture meubel merupakan sektor industri yang sangat unggul di kota Jepara, untuk terus di kembangkan,sehingga konstribusinya terhadap perekonomian memberikan dampak kemajuan.

\section{TINJAUAN TEORI}

Menurut L.M.F Purwanto,2006 dalam buku arsitektur mampu memenuhi standar kenyamanan penggunanya,sehingga komponen didalamnya produk arsitektur tropis.

Menurut teori dari Mc.Lam (2006) dalam buku Arsitektur dan kenyamanan thermal (Noor Cholis,2016) tujuan arsitektur tropis meliputi:

1. Memberikan kenyamanan dan penerapan kesan tropis.

2. Fungsional sesuai kebutuhan pengguna.

3. Efisiensi energy bangunan.

4. Memberikan ciri khas arsitektur publik

Cirikhas iklim tropis lembab. Menurut Lipsmeier,1994: 18 sebagai berikut:

1. Presipitasi: curah hujan tahunan 500$1250 \mathrm{~mm}$.Musim kering sedikit hujan,dan musim hujan berbeda setiap saat.

2. Kelembapan: kelembapan absolut (tekanan uap) cukup tinggi,sampai 15 mm selama musim kering,pada musim hujan $20 \mathrm{~mm}$. Kelembapan relative berkisar 20-85\% tergantung musim.

\section{METODOLOGI PERANCANGAN}

\section{- Pendekatan Aspek Kontekstual}

Tata letak tapak

Lokasi berada di Jln. Jepara-Bangsri Muyoharjo 1 Muyoharjo Kec. Jepara Kab. Jepara Kec.Jawa Tengah 59431, dengan luas lahan $17.350 \mathrm{~m} 2$, dengan arah orientasi menghadap ke selatan, dengan batasan tapak sebagai berikut: Lokasi ini dipilih karena memiliki aspek pencapain yang sesuai kriteria bangunan industri meubel,Potensi tapak sangat mendukung dekat dengan industri meubel furniture serta fasilitas publik maupun transportasi umum.

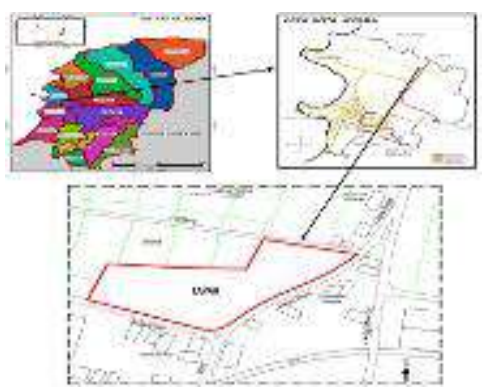

Gambar.1 Analisa Tapak Terpilih

Batas-batas tapak

Utara :Lahan Kosong dan Sanggar Ukir Ragastina Art.

Selatan :Permukiman,WAW antique Jepara, dan kerajinan unik.

Timur :Permukiman dan Beautiful Home

Barat :Permukiman,Pabrik Elegant Furniture Handicraf.

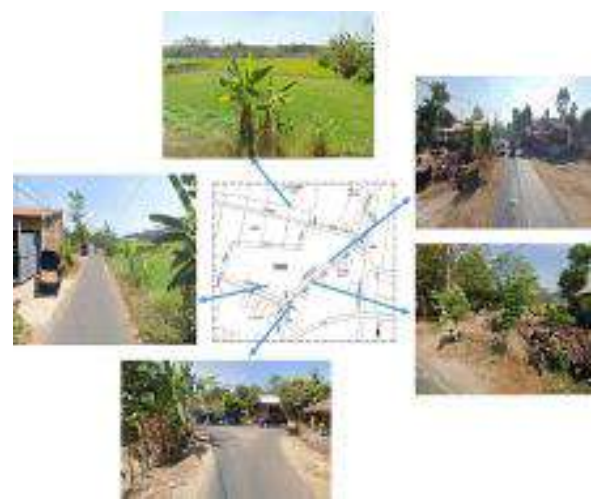

Gambar.2 Batasan Tapak

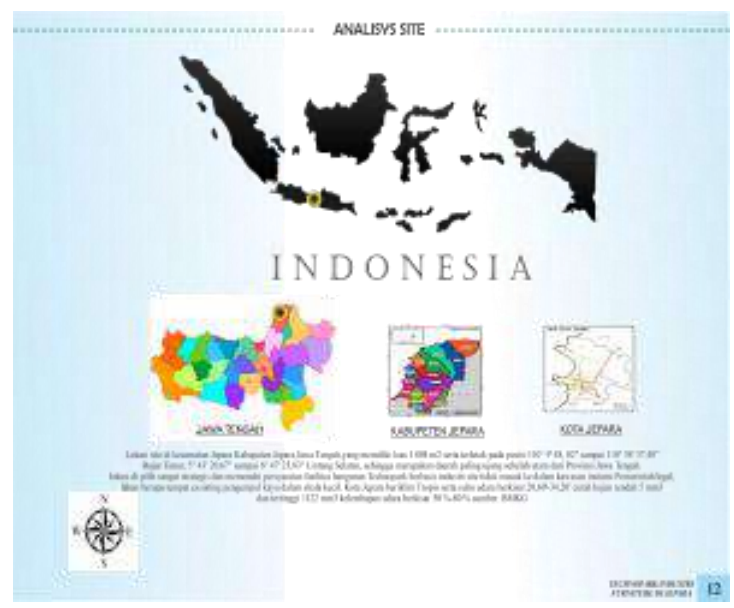

Gambar 3.1 Analisa Tapak 
- Pendekatan Aspek Fungsional

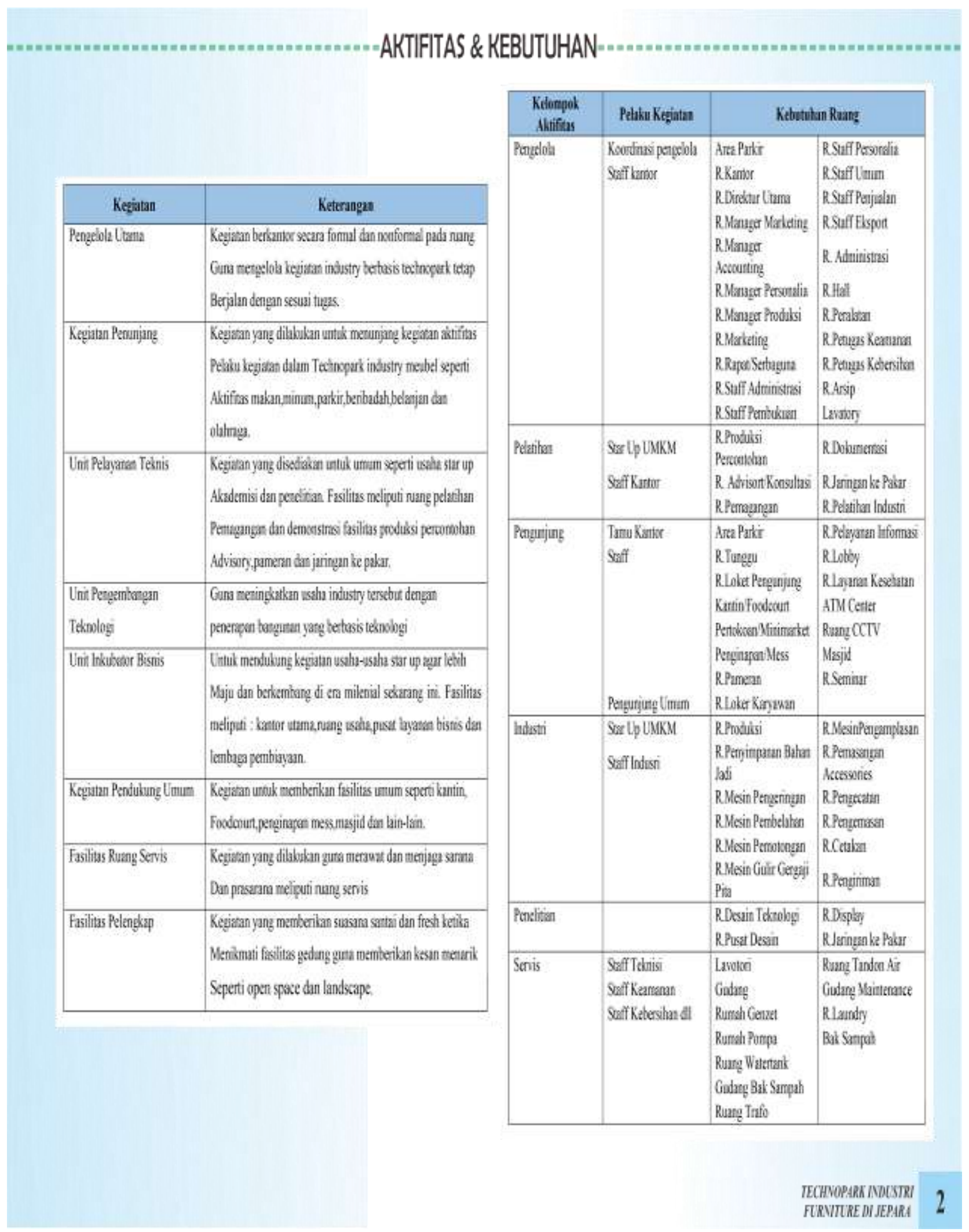




\begin{tabular}{|c|c|c|c|c|c|}
\hline Sana Reag & Junlat & Sirkatus & Las(n:) & Iotal (nt) & Sumiter \\
\hline 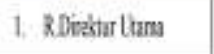 & Ithit & 305 & $16,80 \mathrm{mt}^{\mathrm{t}}$ & $2191 \mathrm{~m}^{2}$ & NAD \\
\hline 2. RDiek̀tur Lhum & | Itat & 914 & $1300 \mathrm{R}^{\mathrm{B}}$ & $1817 \mathrm{~m}^{7}$ & NAD \\
\hline 1. RMuser Xulketiy & Itoil & 304 & $14.60 \mathrm{rt}^{*}$ & $1858 \mathrm{mi}^{2}$ & NAD \\
\hline 4. RMasuer Acoututing & 1tut & $3 S$ & $1600 \mathrm{~m}^{2}$ & $1848 \mathrm{~m}^{2}$ & NAD \\
\hline 5. RManget Persoralie & $\mathrm{Itht}$ & $\mathrm{MH}$ & $14,000 \mathrm{rth}^{-1}$ & $1818 \mathrm{mr}^{2}$ & NAD \\
\hline 6. RMmager Poodilsi & I Unit & 38 & $1460 \mathrm{~m}^{2}$ & $1858 \mathrm{~m}^{2}$ & MD \\
\hline 7. RMatangy & Ithit & 304 & $1460 \mathrm{~m}^{f}$ & $1858 \mathrm{~m}^{2}$ & NAD \\
\hline 8. RSetagntra & Itan & Nos & $14.64 \mathrm{rt}^{2}$ & $2 \times 18 \pi^{2}$ & NAB \\
\hline 9. RStuff Átministrai & Ithit & 304 & $1464 \mathrm{nit}$ & $19,83 \mathrm{~m}^{2}$ & NAD \\
\hline 10. RStaff Ptuthisisn & I thit & 314 & $14,64 \pi^{\circ}$ & $19,0.15 \mathrm{~m}^{2}$ & NAD \\
\hline 11. RSiafíPersagh & Ithit & $3 x$ & $14.64 \mathrm{mt}^{2}$ & $19.83 \mathrm{~m}^{2}$ & NAD \\
\hline 12. Rstufflumm & I thit & \$s & $14,64 \mathrm{at}^{\mathrm{i}}$ & $19,83 \mathrm{~m}^{2}$ & NAD \\
\hline 13. R.Stafferjuln & $1 \mathrm{lnt}$ & ys & $14,64 \pi^{2}$ & $19.01 \mathrm{~m}^{2}$ & NAD \\
\hline 14. RStuff Eksporat & I thit & 34 & $14.6 \mathrm{~m}^{2}$ & $19,13 \mathrm{~m}^{2}$ & NAD \\
\hline 15. R.4minisisnsi & Itrit & $m s$ & $1466 \mathrm{~m}^{2}$ & $19,13 \mathrm{x}^{2}$ & NAD \\
\hline 16. Rith & $1 \mathrm{ltat}$ & 344 & $48,4 \pi$ & $19,13 \mathrm{~m}$ & MD \\
\hline 17. Renalat & I Lift & 38 & $44.3 \mathrm{~m}^{2}$ & $31,61 \mathrm{~m}^{2}$ & NAD \\
\hline 18. R.Patags Kearnaran & Ithit & 34 & $3,03 \mathrm{mr}^{2}$ & $4,00 \mathrm{nt}^{2}$ & NAD \\
\hline 19. Rusip & I tha & MS & $10 \mathrm{nt}^{2}$ & $1 \mathrm{~s}, 10 \mathrm{r}^{2}$ & NAD \\
\hline 20. Toìt Fria (Uninin) & then & MS & $15.50 \mathrm{mf}$ & $20.15 \mathrm{~m}^{2}$ & NAD \\
\hline 21. Tolet fhis & Itrit & 325 & $8,3,8 \pi^{2}$ & $10 \% \mathrm{~m}^{2}$ & NAD \\
\hline 22 Toikt Wints & Ithat & 35 & $9,26 \pi r^{\circ}$ & $12.13 \mathrm{mr}$ & NGD \\
\hline \multicolumn{4}{|c|}{ Jenthe Tral Lusen Kesdentan } & $317 \times \mathrm{m}^{2}$ & \\
\hline \multicolumn{4}{|c|}{ Sitkalsi Lutar Rasag $30 \mathrm{~S}$} & $113,34 \mathrm{nz}$ & \\
\hline \multicolumn{4}{|c|}{ Jenbh Tctal Keslunutan Lusa } & 49..16in? & \\
\hline
\end{tabular}

\begin{tabular}{|c|c|c|c|c|c|}
\hline Sullay! & Juth & Sributin & Lasin| & Tiral(iet) & Sabter \\
\hline 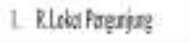 & $1 \mathrm{tw}$ & 4t) & $x$ करे th & $1035 \mathrm{n}^{2}$ & NAD \\
\hline 2. RLebaKryma & tha & as & 173t & W, at & SAD \\
\hline 1. Retwonitimasik & 2 tat & 315 & 13364 & $1136 \mathrm{~F}^{2}$ & $\mathrm{NAD}$ \\
\hline 4 R.ung linulots & that & 4t5 & IEA at & $25 \%$ & NAD \\
\hline 4. Rlapoukinton & 1tat & $\mu \%$ & $931 x^{1}$ & $12,10 \mathrm{nt}$ & SAD \\
\hline \multicolumn{4}{|c|}{ 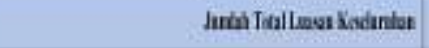 } & tannt & \\
\hline \multicolumn{4}{|c|}{ Sthasi Autr Bang 35} & $5,13 n 2$ & \\
\hline \multicolumn{4}{|c|}{ 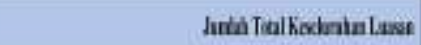 } & 199:nt & \\
\hline
\end{tabular}

\begin{tabular}{|c|c|c|c|c|c|}
\hline Karslluą & Juth & Sindax & $\operatorname{Lax}|n|$ & Tialinz) & Suster \\
\hline 1. RPargugan & stit & 415 & 19A at & $15 \mathrm{rr}^{2}$ & A \\
\hline 2. RSartiptand & loth & 45 & $4(4)$ & $\operatorname{sc} 60 \mathrm{a}^{2}$ & As \\
\hline 1 RDhoratid & Ita & $3:$ & DA8 $\mathrm{nf}$ & p,128 & Ne \\
\hline 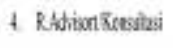 & Ithit & 315 & 2,4 tit & $1452 \mathrm{r}^{2}$ & As \\
\hline 3. Riniznínitiz & Itas & as & 136t & $13120^{7}$ & Ai \\
\hline \multicolumn{4}{|c|}{ 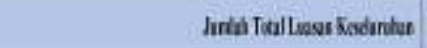 } & Ix:That & \\
\hline \multicolumn{4}{|c|}{ Selabs Autralang 39: } & $2017 \mathrm{mt}$ & \\
\hline \multicolumn{4}{|c|}{ Jurih Tral Kodratun Luxo } & UWAsal & \\
\hline
\end{tabular}

\begin{tabular}{|c|c|c|c|c|c|}
\hline Kasknay & Juth & Sirtaté & Lwin:) & Titalin? & Suntr \\
\hline \multicolumn{6}{|l|}{ 1. RDesintibiogi } \\
\hline RPas Kujia & Iten & ms & 12,40r & 1412 tr & 5 \\
\hline 2. P.Pras Desen & thet & $30 \leqslant$ & $12,46 \mathrm{r}^{\circ}$ & Ka:lin & s \\
\hline 2. Rring Ke?iar & Itai & 30 & $11,46 e^{2}$ & $14,7 x^{2}$ & Af \\
\hline $\begin{array}{l}\text { 4. RLade Dosin } \\
\text { firnes }\end{array}$ & Itat & $3 \mathrm{~s}$ & $1326 \mathrm{e}^{\circ}$ & $17,16 x^{2}$ & 45 \\
\hline 1. Ronatit & tht & 35 & $14 \pi, 4 \pi^{2}$ & K): $\frac{1}{8}$ & so: \\
\hline 6. ROExinifuriss & itht & $3 \%$ & Bfert & 16llter & As \\
\hline
\end{tabular}




\begin{tabular}{|c|c|c|c|c|c|}
\hline Sam Reat & Janlat & Sritabe & $\begin{array}{l}\text { Ian } \\
\text { (nd) }\end{array}$ & Inding) & Sinker \\
\hline 1.REsinale & Itut & $30 \mathrm{~s}$ & $\begin{array}{c}{[1,060} \\
\mathbf{I f}\end{array}$ & $2191 \mathrm{n}^{2}$ & $X A D$ \\
\hline 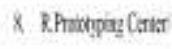 & tht & 705 & $90 \mathrm{n}^{2}$ & $21,91 \mathrm{n}^{2}$ & SAD \\
\hline RDisy & & & & & \\
\hline 9. RPonkzogn & Itui & $36 \%$ & $9 i m \mathbf{x}^{2}$ & $1191 \mathbf{r}^{\prime}$ & KAD \\
\hline $\begin{array}{l}\text { I0. R. Godrs funtux } \\
\text { hom } \\
\end{array}$ & Ithe & 365 & $|n|$ & $1191 \mathrm{r}$ & SAD \\
\hline 11. RTélagus & 1 tha & 368 & $3 n^{2}$ & $2191 \mathrm{rr}^{2}$ & KAD \\
\hline 12. R.Send Sigkar & lint & $30 S$ & $31 a^{2}$ & $11,91 \mathrm{er}^{2}$ & XAD \\
\hline 13. R. Gutre Potidn & Itit & $10 \%$ & $28 \mathrm{~m}^{2}$ & $2191 \mathbf{n}^{2}$ & $\mathrm{KAD}$ \\
\hline 14. Initit & Ithe & $16 \%$ & $8 \mathrm{nt}^{2}$ & $21,91 \mathbf{r}^{2}$ & $X A D$ \\
\hline \multicolumn{4}{|c|}{ Jutid Tod Lasn Kesinata } & L.Th31 a? & \\
\hline \multicolumn{4}{|c|}{ Setulsi Atar Ruy 34} & S4L55 a? & \\
\hline \multicolumn{4}{|c|}{ Juntal Tol Kaxtunton Lasa } & $228453 x ?$ & \\
\hline
\end{tabular}

\begin{tabular}{|c|c|c|c|c|c|}
\hline Sam Rong & Junbl & Sckbiai & Las $(n \mid t)$ & Tal $|\mathbf{n}\rangle$ & Sutior \\
\hline \multicolumn{6}{|l|}{ Katnetod Lon: } \\
\hline L 34anbar & 2llai & 165 & $10824 e^{2}$ & $14136 \mathbf{n}^{2}$ & $\mathrm{NAD}$ \\
\hline 2 aburosdor & 2lloi & $30 \%$ & $168 \times \mathrm{ar}^{2}$ & $1+136 \mathrm{r}^{\circ}$ & NDD \\
\hline 3. Tris Patliave & Ithi & 305 & $53 \mathrm{ix}^{2}$ & $x, 15 a^{2}$ & NAD \\
\hline 4 Trist: Ptu & l the & 365 & $84 \pi^{2}$ & $10 \times \mathrm{n}^{2}$ & NDD \\
\hline 5. 3atparib & I thet & 45 & $11 t^{2}$ & $13 \mathbf{n}^{2}$ & At \\
\hline \&. Tolathri & Ithit & $16 \%$ & $9 x 0^{2}$ & $120 \pi^{t}$ & is \\
\hline $\begin{array}{l}\text { 2. Depr Bosik Dopr } \\
\text { Sor }\end{array}$ & I lik & as & $139 x^{2}$ & $136 \pi^{2}$ & As \\
\hline if lenx & Ithi & 505 & $3,3 \pi^{2}$ & $49 r^{\circ}$ & ds \\
\hline 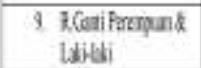 & 1 tht & 368 & $15 \pi^{2}$ & $3 \mathrm{er}$ & As \\
\hline 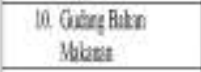 & I thi & 165 & $2 n^{2}$ & $13 \pi^{\prime}$ & As \\
\hline IL. BStrint & the & 100\% & $24 \pi^{2}$ & $46 r^{\prime}$ & As: \\
\hline 12 kxrive & Itts & isos & $24+t^{2}$ & $46 \mathrm{er}^{2}$ & As \\
\hline 13. ATMCere & Ithe & 465 & $13,4 a^{2}$ & $10.91 \pi^{2}$ & As \\
\hline 14 3007Y & the & 145 & [1\% ते & $1551 n^{1}$ & NAD \\
\hline $\begin{array}{l}\text { 15 Mbeyd } \\
\text { PSrallana }\end{array}$ & I Irí & $36 \%$ & $72 \mathbf{r}^{2}$ & \$s: $\mathrm{n}^{4}$ & $m M$ \\
\hline 16 35rabistas & Ithi & 365 & के & $4 x+a^{2}$ & $m$ \\
\hline 17. RYirind danVirbor & Ithi & 305 & $5 \pi^{\frac{1}{2}}$ & $6,9 \mathrm{tr}^{\circ}$ & As \\
\hline 18. Merotan Patras & lith & 305 & $436 \mathrm{tr}^{2}$ & $3 / 5 u^{2}$ & NAD \\
\hline 19. This Pondthan) & Ithe & 365 & 1551 in $^{2}$ & $20,15 \mathrm{n}^{2}$ & NQD \\
\hline x Takthi & Itiri & $16 \mathrm{~K}$ & $830 \mathrm{x}^{2}$ & $16 \% \pi^{1}$ & MD \\
\hline 21. Tastorati & 1 thit & 365 & 9.56 it & 120 & NDD \\
\hline 2. Rustupi & Ita & 305 & 870 at & $11,31 a^{1}$ & NAD \\
\hline \multirow[t]{4}{*}{ 21. 3.thtalus } & Ithe & 168 & $80 \mathrm{r}^{2}$ & $11,31 \mathbf{n}^{2}$ & NDD \\
\hline & \multicolumn{3}{|c|}{ Junbl Trallawe Kischnan } & $\begin{array}{l}115635 \\
\text { a! }\end{array}$ & \\
\hline & \multicolumn{3}{|c|}{ Sintudiatar baset tin } & a2.74 a? & \\
\hline & \multicolumn{3}{|c|}{ 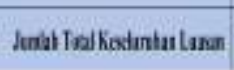 } & $\begin{array}{l}4989 \\
\mathrm{n} !\end{array}$ & \\
\hline
\end{tabular}

\begin{tabular}{|c|c|c|c|c|c|}
\hline Nanilair: & Janit & Sratus & $\begin{array}{l}\text { Lan } \\
\text { [n: }\end{array}$ & Istal(a)] & Sunkt \\
\hline $\begin{array}{l}\text { L. RParirpmi } \\
\text { Butalat }\end{array}$ & Ittit & $16 \mathrm{~s}$ & $3 \mathrm{st}^{4}$ & $1,91 \mathrm{r}^{\circ}$ & XAl \\
\hline 2 RPagenzen & Ithi & $10 \%$ & $34 \mathrm{tr}$ & $1,91 \mathbf{n}^{2}$ & SAD \\
\hline 3. RPabxita & Itit & 365 & I $\mathrm{C} \mathrm{s}^{2}$ & 11,91 tri & XID \\
\hline I RPenworen & Itat & 365 & $102 x^{2}$ & ม., & XAD \\
\hline 5. R.Galr Eoggiipa & $1 \mathrm{tht}$ & 508 & $18 \mathrm{n}^{2}$ & $11,91 \mathbf{r}^{2}$ & XAD \\
\hline 6. RCotin & $1 \mathrm{tat}$ & 165 & $18 \mathrm{~s}^{2}$ & $21,91 \mathrm{r}^{2}$ & $\mathrm{XAD}$ \\
\hline 2. RPexurtess & Ita & 108 & $34 \mathrm{r}^{2}$ & $21,91 \times$ & KAD \\
\hline $\begin{array}{l}\text { 8. Renasen } \\
\text { krelina } b \\
\text { hrosire }\end{array}$ & thit & 368 & Wrat & $2191 \mathbf{r}^{\circ}$ & NAD \\
\hline 2. RPegowar & Itat & 165 & 40 & $21,91 \mathrm{n}^{2}$ & SAD \\
\hline til R.Poxenso & $\mathrm{Hea}$ & 365 & $34 \pi^{\prime}$ & $11.91 \%$ & $\mathrm{XAD}$ \\
\hline 11. R.Pogirme & tht & $36 \%$ & $3 n^{2}$ & म19 $18 \mathrm{r}^{2}$ & XAR \\
\hline \multicolumn{4}{|c|}{ Juth Tol Lzse Kodanda } & $1.362 a^{2}$ & \\
\hline \multicolumn{4}{|c|}{ Sirtulaikar Rambु } & $5645 a^{2}$ & \\
\hline \multicolumn{4}{|c|}{ Justa Teal Xostuntiso Lasa } & $17 \pi 2 / 8 \mathrm{a}^{\prime}$ & \\
\hline
\end{tabular}


- Pendekatan Aspek Arsitektural

Bangunan Technopark di rencanakan dengan menerapkan pendekatan ArsitekturTropis.Pendekatan Arsitektur Tropis bertujuan untuk menyelesaikan permasalahan pada bangunan khususnya di bidang industry guna mendapatkan bangunan yang ramah lingkungan,sejuk,serta pertimbangan kenyamanan bagi pengguna dalam ruangan. Dengan ini bangunan technopark yang bergerak di bidang industry lebih mengoptimalkan persyaratan arsitektur tropis serta memberikan referensi prinsip desain baru yang menarik pada bangunan industry.

\section{A. Konsep Eksterior Bangunan}

Konsep tampilan eksterior bangunan atau fasade dalam perencanaan dan perancangan Technopark Industri Furniture Meubel dengan pendekatan arsitektur tropis. Material yang digunakan GRC/roster,batu alam,bata expose,kaca dan sun shading dari ACP serta pemberian tanaman rambat disekitar roof garden/plat canopy. Konsep material dapat dijelaskan sebagai berikut:

1. Penempatan kaca di area tertentu sesuai fungsi ruang.

2. PengunaanmaterialGRC/roster/batu alam berguna untuk sirkulasi udara alami,pencahayaan alami dan memberikan kesan lokalitas daerah tersebut.

3. Pengunaan laser cutting ACP bermotif batik kawung sebagai sun shading dan memberikan nilai estetika.

4. Penempatan tanaman rambat lee kwan yew di sekeliling roof garden/plat canopy agar memberikan kesejukan disekitar tapak.

5. Untuk finishing ke warna tidak terlalu cerah agar kesan tropis dan lokalitas tetap ada.

\section{A. Konsep Interior Bangunan}

Konsep tampilan interior bangunan dalam perencanaan dan perancangan Technopark Industri Furniture Meubel dengan pendekatan arsitektur tropis. Dalam bangunan lebih mengutaman kenyamanan,fungsional dan estetika lokalitas di dalam ruangan. Dengan penjelasan sebagai berikut :

1. Lantai homogenose tile dan lantai vynil agar terkesan mewah dan lokalitas expose alami.

2. Wall panel ditempatkan diarea tertentu seperty ruang pertemuan,lobby dst agar memberikan suasana berbeda.

3. Penggunaan Plafon kisikisi/Gipsum sesuai dengan fungsi ruang.

\section{C.Konsep Struktur}

\section{Sub Struktur}

Jenis pondasi yang digunakan footplat dan tiang pancang. dipergunakan pada kondisi tanah sesuai tapak dan bentang lebar seperti gudang industri dan fasilitas gedung yang ada di Technopark Industri Furniture Meubel.
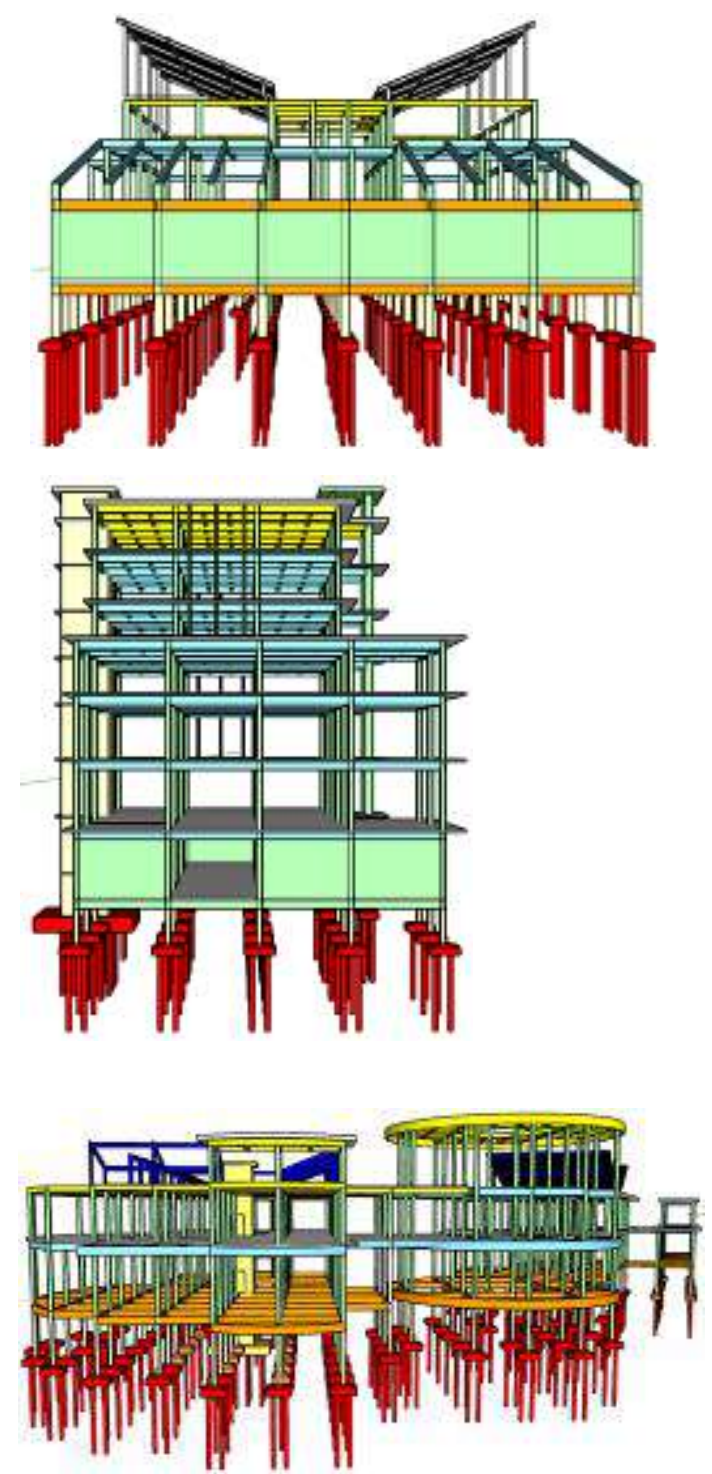
Gambar 3.2 Struktur Footplat dan Tiang Pancang Sumber : Analisa Penulis,2021

\section{Super Struktur}

Pada struktur tengah menggunakan struktur sloof,kolom dan balok beton maupun baja sesuai dengan fungsi bangunan.
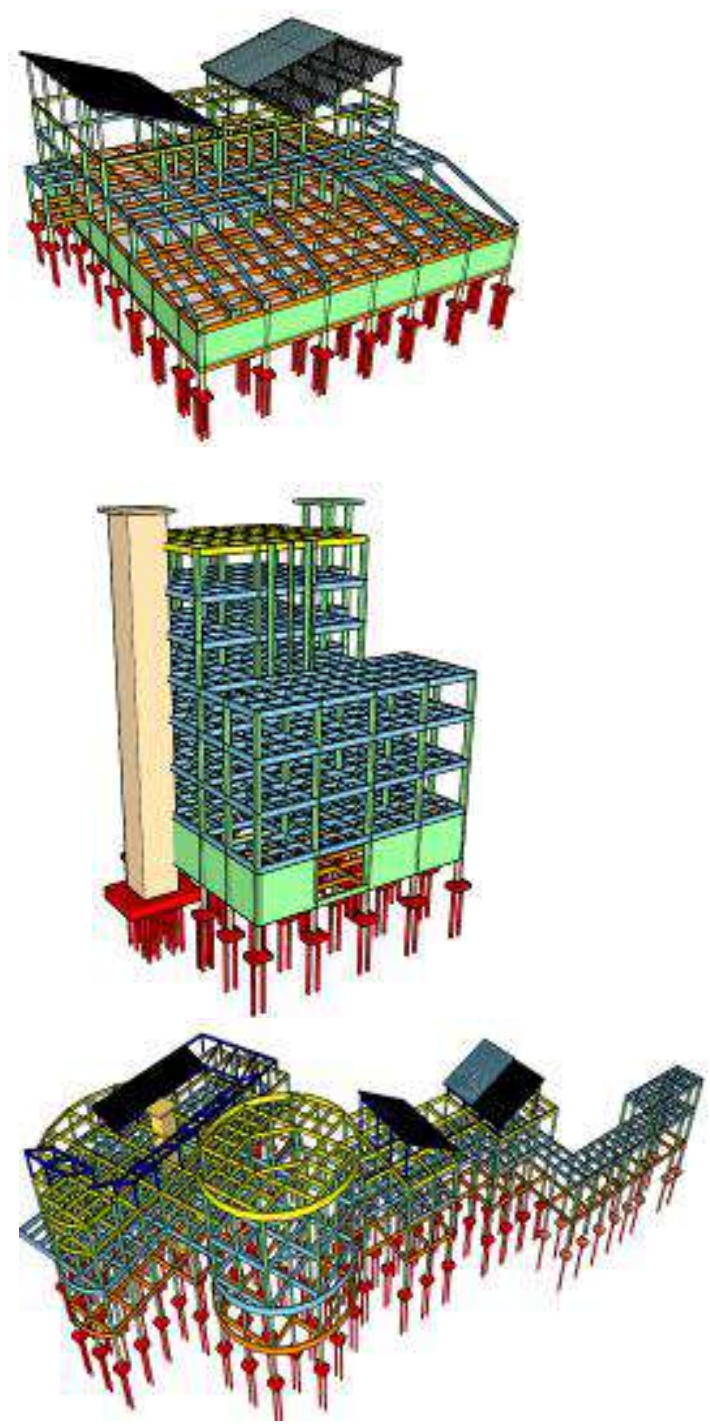

Gambar 3.3 Struktur Kolom beton,baja dan balok

\section{Upper Struktur}

Untuk struktur atas sebagian menggunakan struktur beton, baja dan jenis genteng sesuai dengan fungsi bangunan.
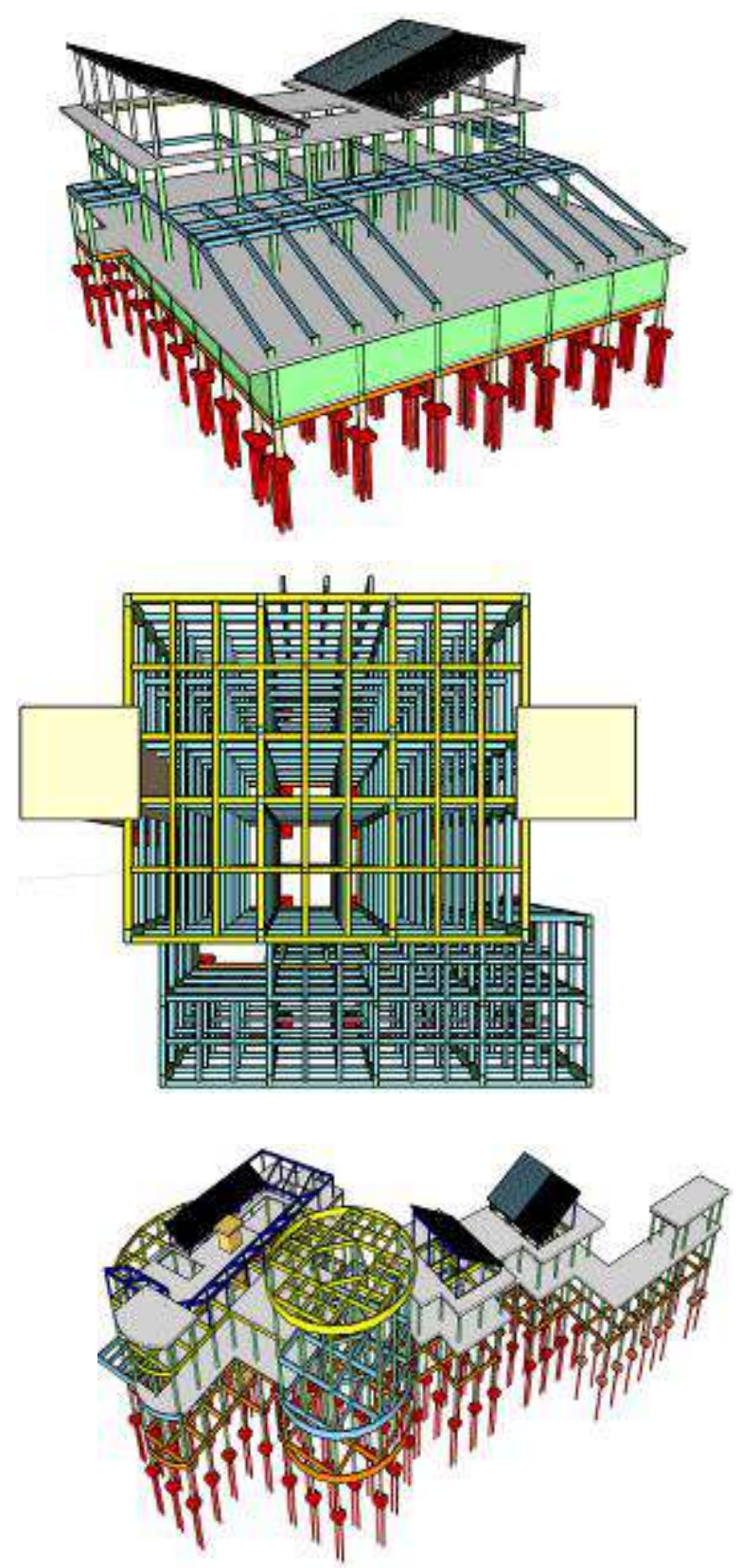

Gambar 3.4 Struktur Kolom beton,Baja dan balok 


\section{PEMBAHASAN}

Berdasarkan perhitungan besaran ruang pada bab sebelumnya,di dapatkan luasan :

\begin{tabular}{|c|c|c|}
\hline \multicolumn{3}{|c|}{ LUAS KEBUTUHAN FASILTTAS } \\
\hline No & Program Kebutuhan Reang & $\begin{array}{c}\text { Luas } \\
\text { Ruang }\end{array}$ \\
\hline 1 & Fasilitas Utama & $491,166 \mathrm{~m}^{2}$ \\
\hline 2 & Fasilitas Penunjang & $160,92 \mathrm{~m}^{2}$ \\
\hline 3 & Fasilitas Unit Pelayanon Teknis (UPT) & $1.086,48 \mathrm{~m}^{2}$ \\
\hline 4 & Fasilitas Unit Pengembangnn Teknologi & $2.218,46 \mathrm{~m}^{2}$ \\
\hline 5 & Fasilitas Unit Inkubator Bisuis & $1.772,68 \mathrm{~m}^{2}$ \\
\hline 6 & Fasilitas Pendukung Umum & $3.054,17 \mathrm{~m}^{t}$ \\
\hline 7 & Fasilitas Servis & $276,94 \mathrm{~m}^{2}$ \\
\hline 8 & Fasilitas Ruang Luar Parkir dan Landscape & $2.400 \mathrm{~m}^{2}$ \\
\hline & Total Keseluruham & $\begin{array}{c}11.460,816 \\
\mathrm{~m}^{2}\end{array}$ \\
\hline
\end{tabular}

Tabel 2.4 Besaran Kebutuhan Luas Bangunan

Perhitungan kebutuhan KDB,GSB dan RTH dengan mengacu pada peraturan RTRW tahun 2017di Kota Jepara adalah sebagai berikut :
- $(\mathrm{KDB})=60 \%$
- $(\mathrm{KLB})=3 \mathrm{Lt}$.
- $(\mathrm{GSB})=10 \mathrm{~m}$
○ $(\mathrm{RTH})=40 \%$

Total Luas Lahan $=17.350 \mathrm{~m}^{2}$.

Luas Lahan $=17.350 \mathrm{~m}^{2}$.

Luas $\mathrm{KDB}=60 \%$.

1.Kebutugan (KDB) $60 \%$.

$=\mathrm{KDB} 60 \%$ x Luas Tapak

$=60 \% \times 17.350 \mathrm{~m}^{2}$.

$=10.410 \mathrm{~m}^{2}$.

2.Kebutugan (RTH) $40 \%$.

$=\mathrm{RTH} 40 \% \times$ Luas Tapak

$=40 \% \times 17.350 \mathrm{~m}^{2}$.

$=6.940 \mathrm{~m}^{2}$.

\section{A. Konsep Terhadap Tata Letak Tapak}

Hasil konsep tapak yang sudah diperoleh dari analisa yang sudah dibuat meliputi :

- Tapak masih berupa lahan kosong tidak ada masalah izin.

o Letak tapak dekat denga fasilitas transportasi umum dan bangunan industry furniture meubel.

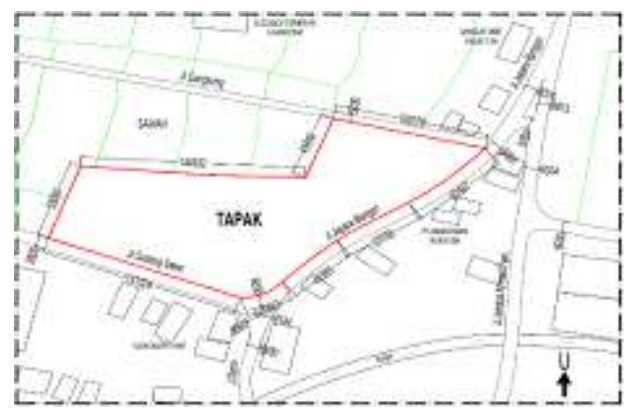

\section{B.Konsep \& Respon Analisa Tapak}

Untuk mengatasi utilitas pada area disekitar tapak dan bangunan dengan cara sebagai berikut:

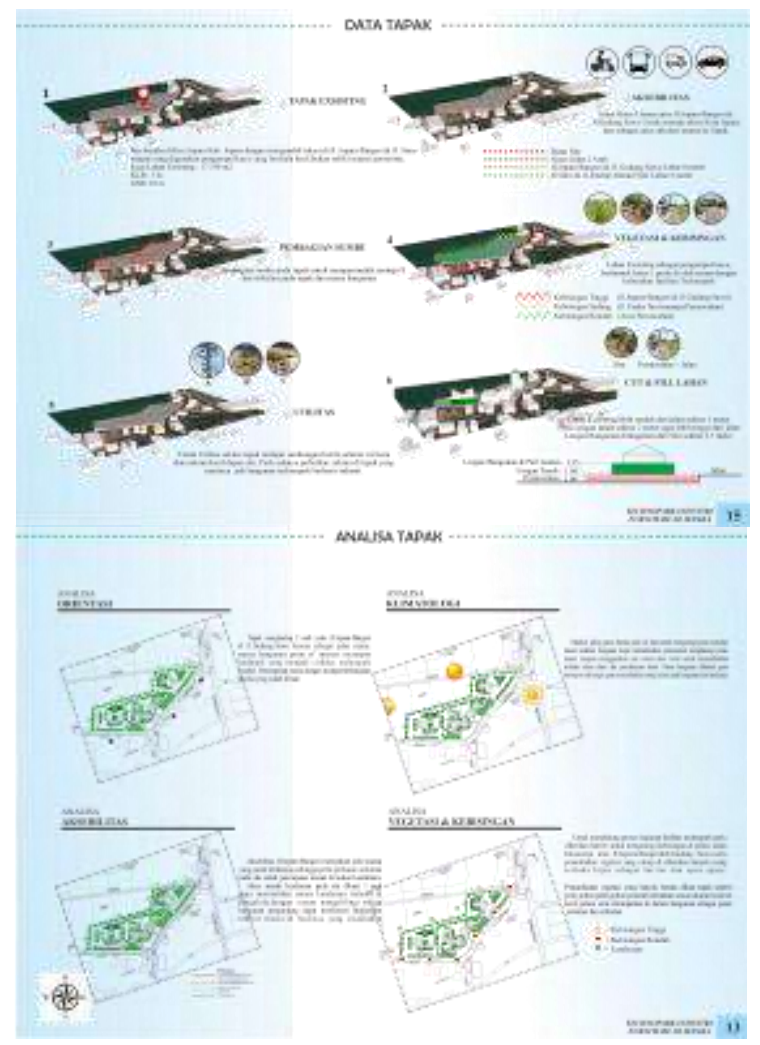

Gambar 3.6 Konsep dan Respon Tapak

\section{C.Konsep Utilitas}

Untuk mengatasi utilitas pada area disekitar tapak dan bangunan dengan cara sebagai berikut:

- Saluran Exsisting yang tersumbat perlu diperbaiki.

- Penggunaan material perkerasan halaman yang memiliki resap air.

- Air hujan dapat dialirkan di sungai buatan guna memberikan kesejukan di area bangunan.

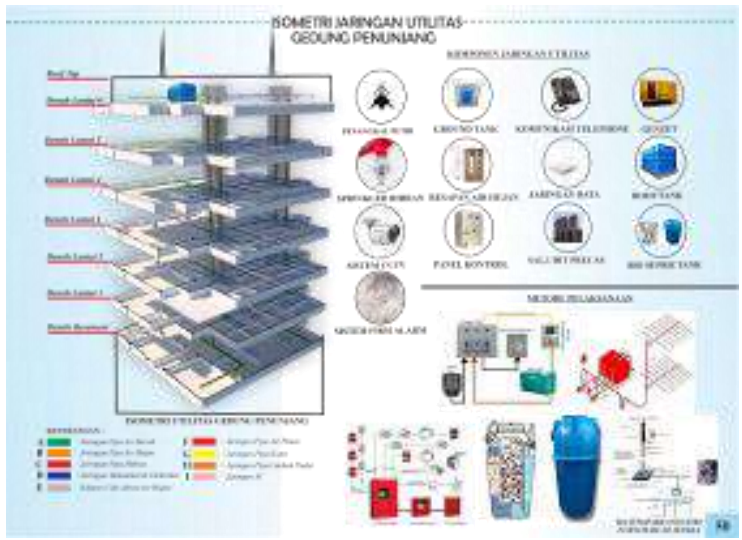




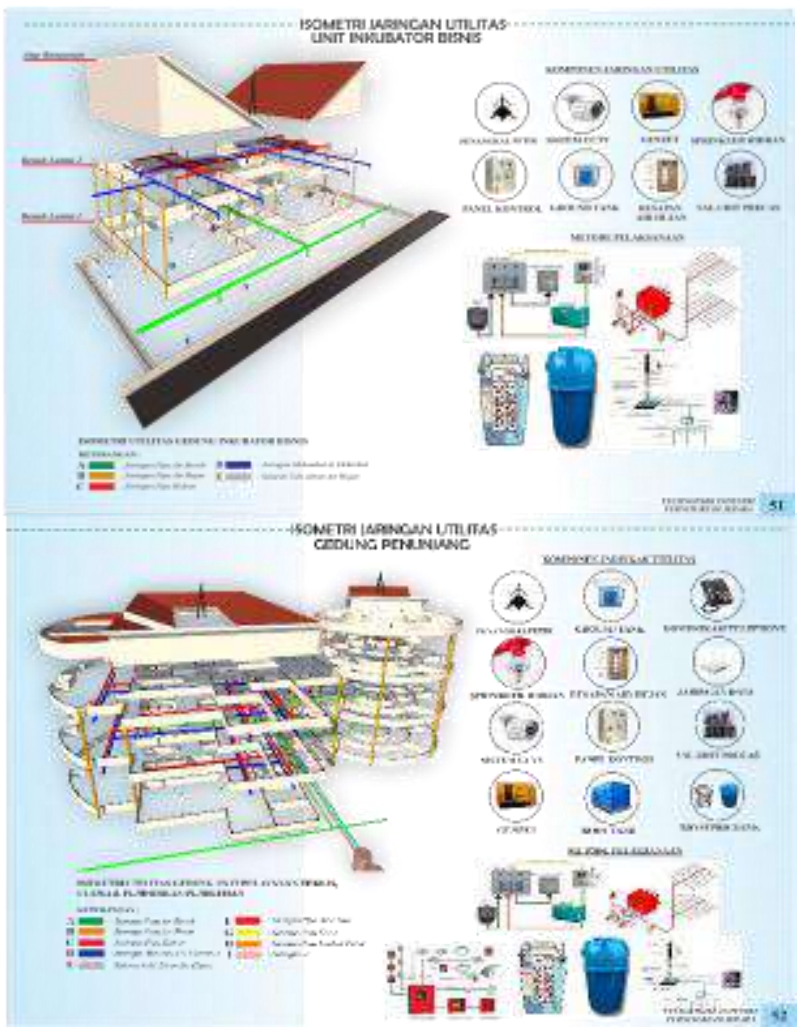

Gambar 3.7 Konsep Utilitas

\section{Konsep Terhadap Zoning Horizontal}

Untuk penempatan massa disesuaikan analisa sebelumnya guna dapat merespon bangunan seperty :

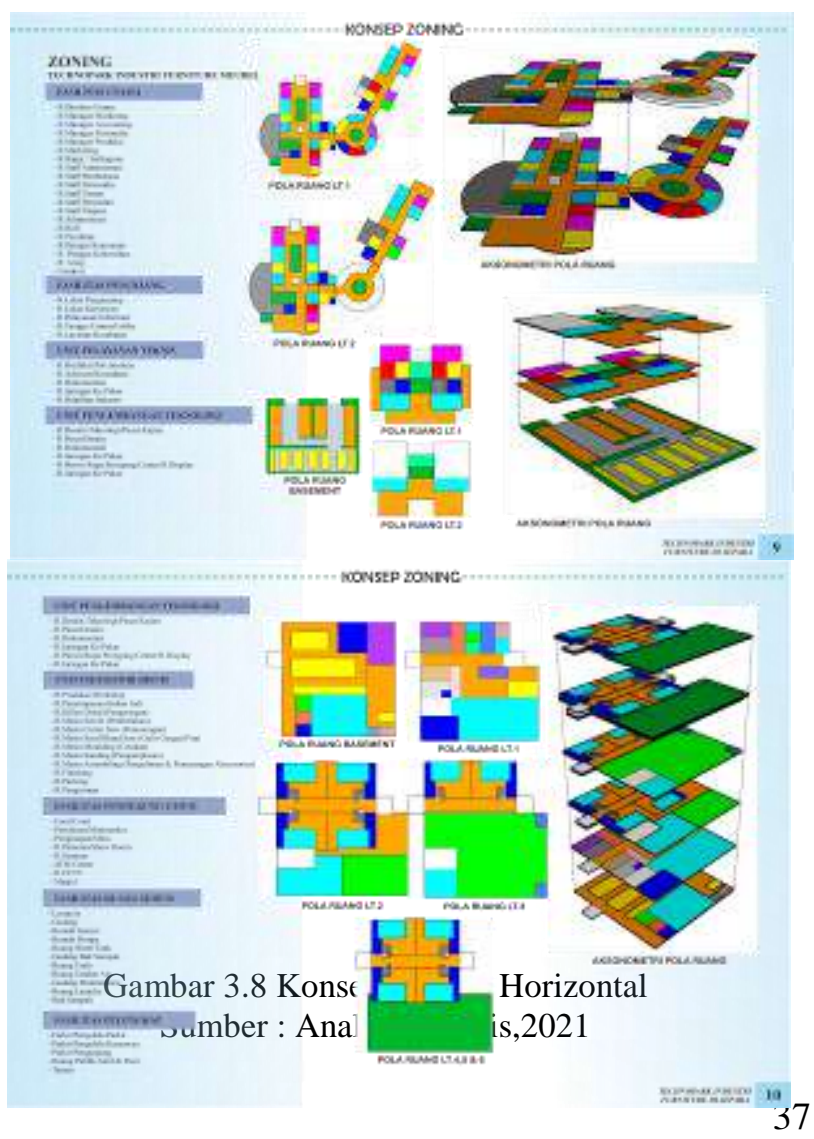

\section{E. Konsep Gubahan Massa}

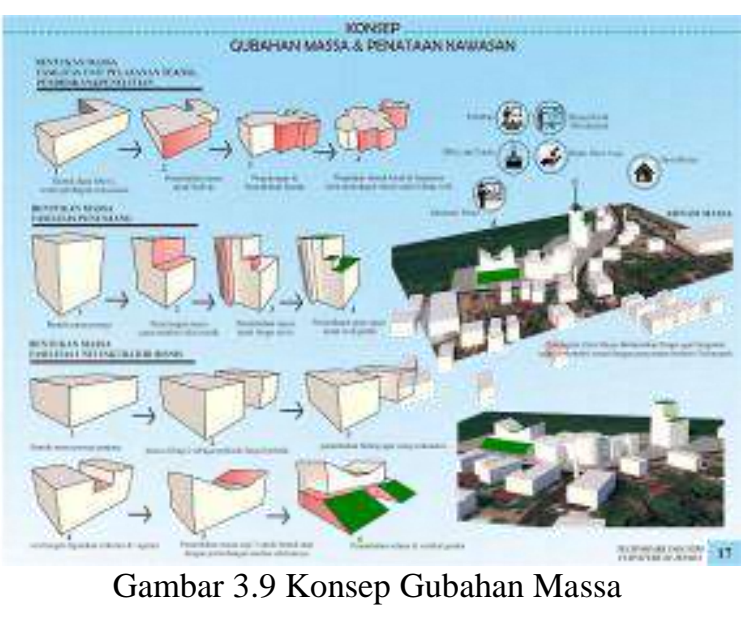

\section{F.Konsep Bangunan Arsitektur}

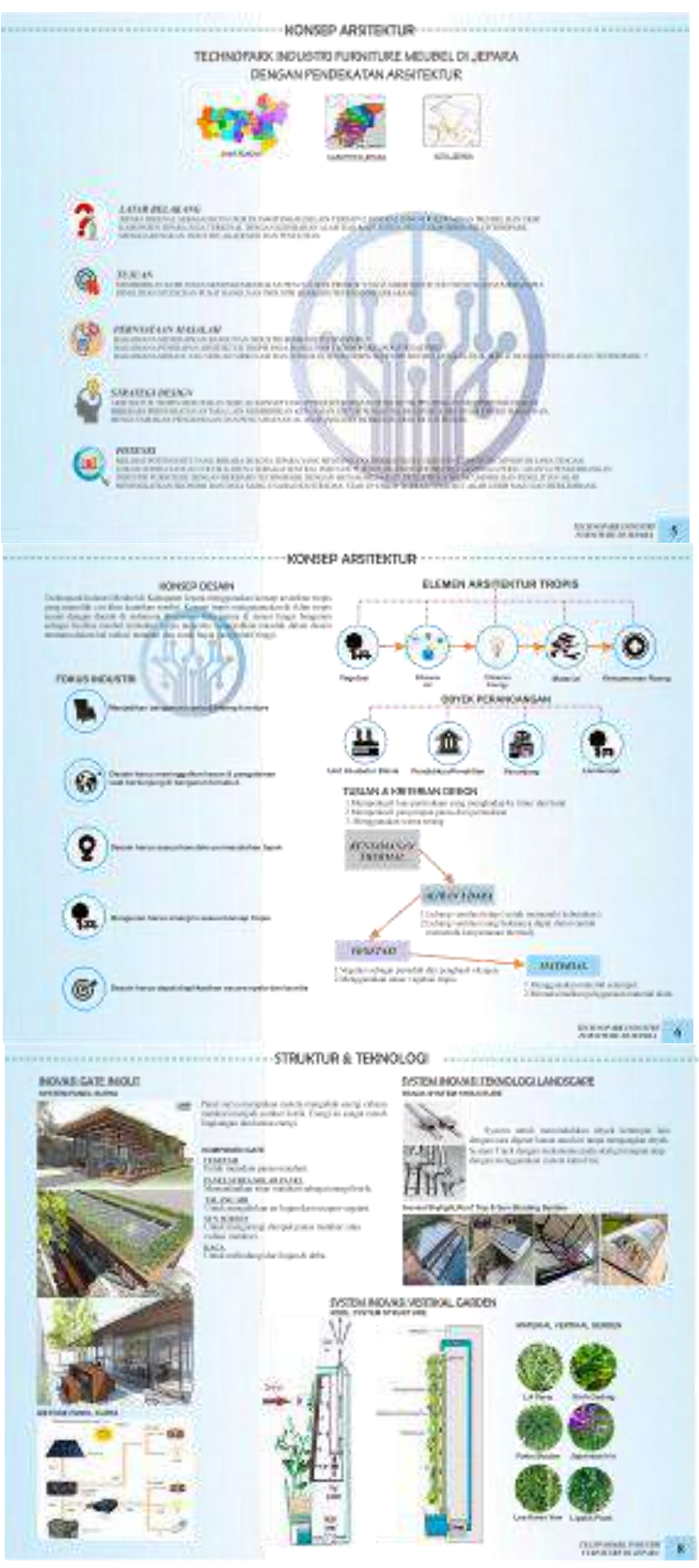




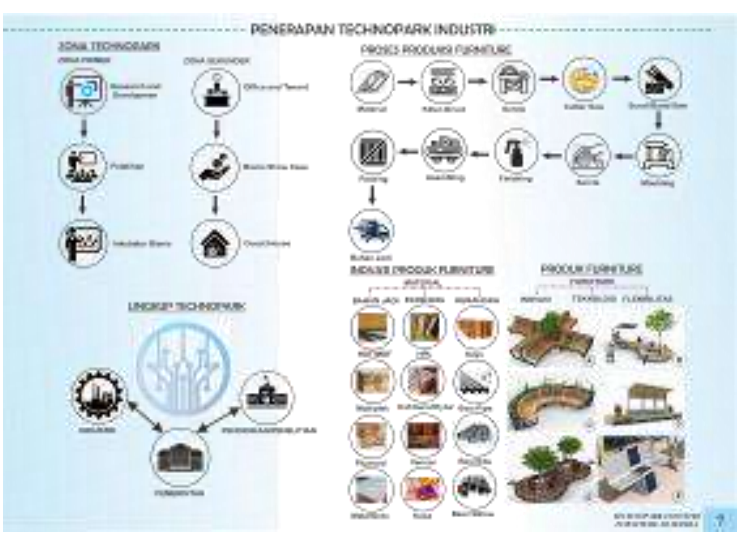

Gambar 3.10 Konsep Bangunan Arsitektur

\section{G. Konsep Gambar Kerja}

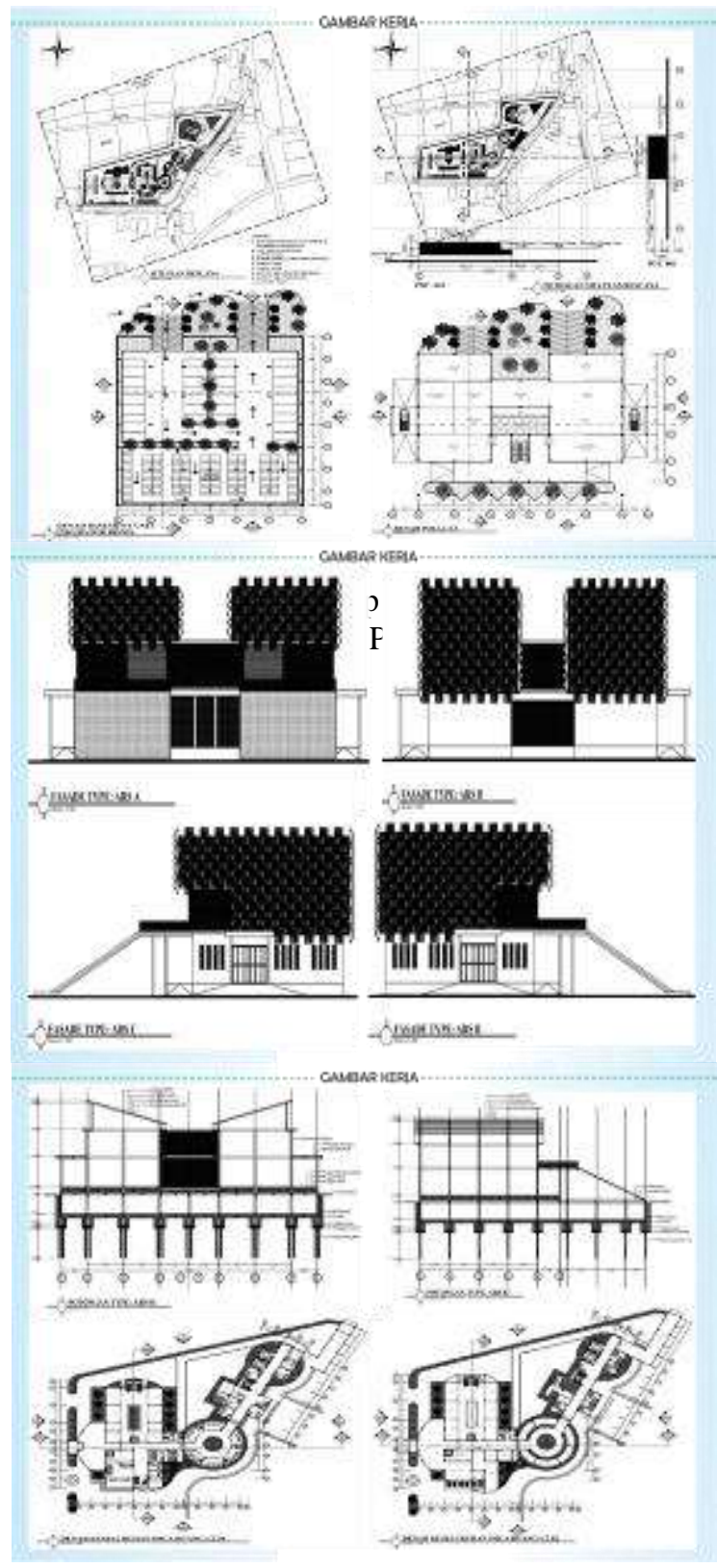

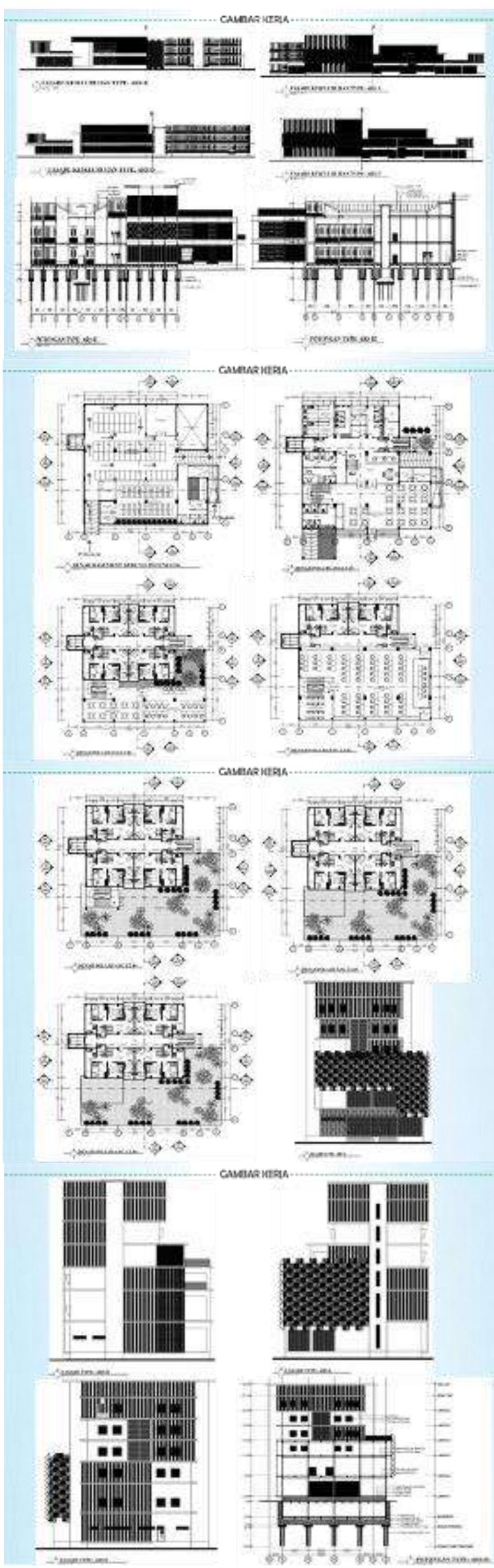

Gambar 3.13 Konsep Visualisasi 3D Interior 


\section{H. Konsep Visualisasi 3D Eksterior}
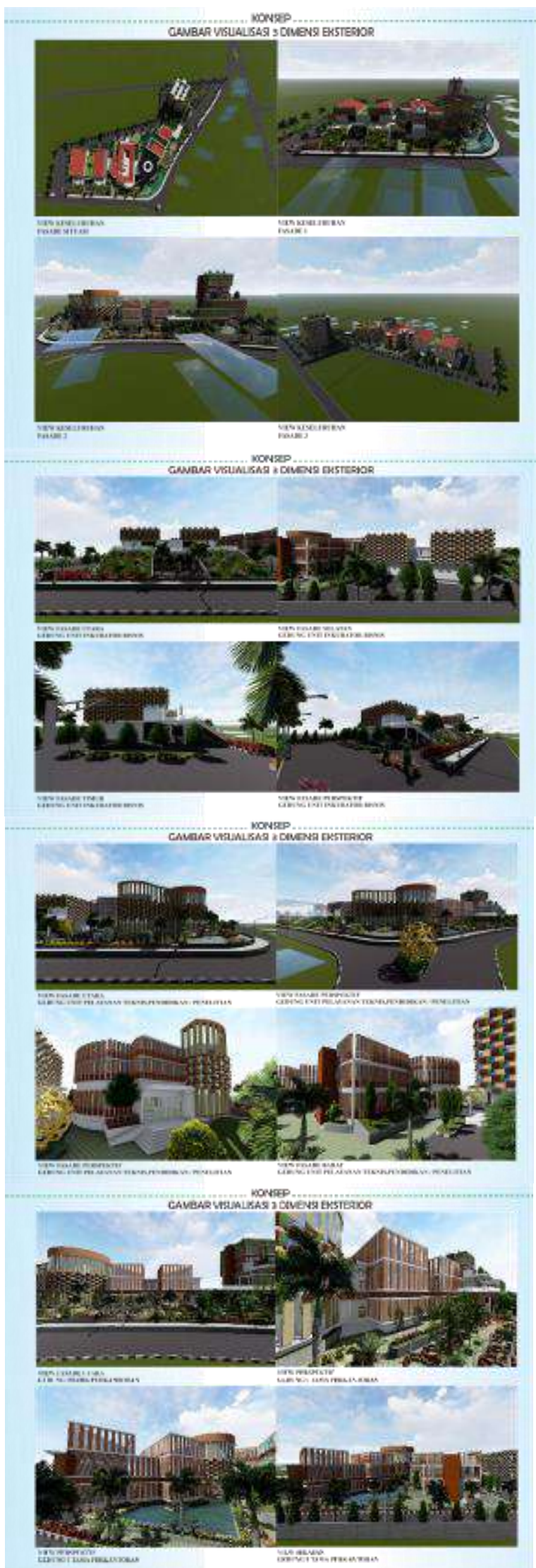

Gambar 3.12 Konsep Visualisasi 3D Eksterior

\section{Konsep Visualisasi 3D Interior}

Cirikhas ukir Kota Jepara dimasukan di dalam interior guna memberikan cirikhas lokalitas hasil industri daerah tersebut.
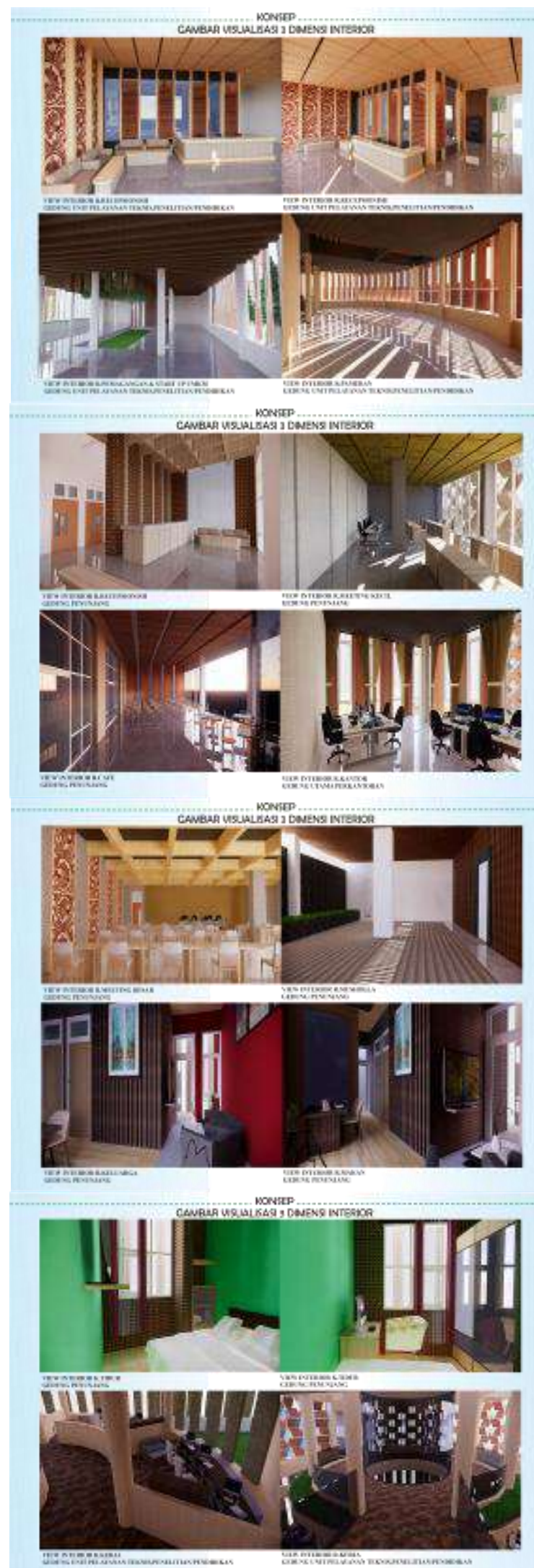


\section{J. Konsep Visualisasi 3D Landscape}

Fasilitas landscape terdapat play ground,taman pasif dan aktif serta terdapat roof garden. Konsep taman menekankan arsitektur tropis guna singkronisasi dengan bangunan nya.

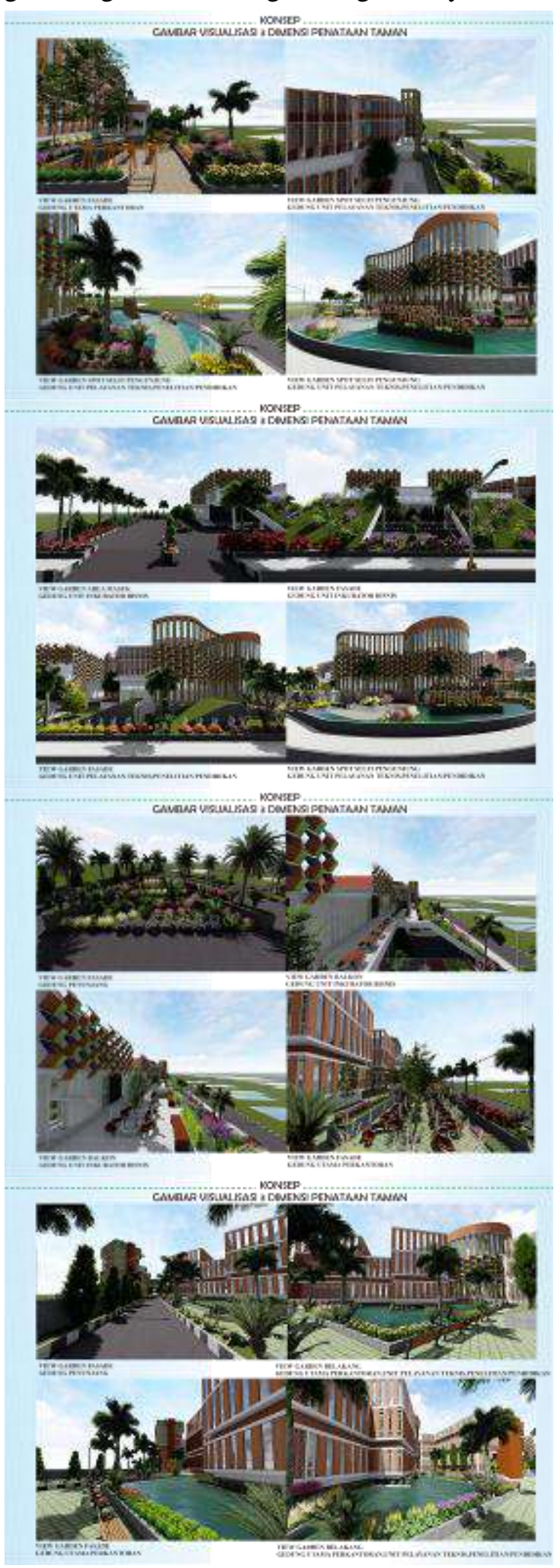

\section{KESIMPULAN}

Bangunan Technopark Industri Furniture Meubel yang bergerak di bidang industri berbasis teknologi di Jepara yang akan di rancang nanti harus memperhatikan beberapa point di antaranya poin visual arsitektur. Berikut ini yang menjadi pertimbangan penerapan bangunan yaitu:

a. Penampilan desain terlihat arsitektur tropis.

b. Lebih menggunakan material epose guna memberikan kenyamanan dan persyaratan tropis.

c. Pemberian vegetasi disekitar tapak dan dalam bangunan untuk memberikan kesejukan dalam bangunan.

d. Penataan massa perlu dipertimbangkan dengan bangunan industri guna fungsi bangunan saling terkoneksi.

e. Penerapan material seperti batu alam,bata expose dst ditempatkan sesuai fungsi bangunan untuk memberikan kesan estetik.

f. Pemilihan warna dipadukan dengan material dan fungsi bangunan agar terkesan menyatu dengan alam.

g. Penggunaan vegetasi disekitar bangunan guna meredam sinar matahari.

Berdasarka poin tersebut,bangunan ini dirancancang menampilkan visual arsitektur sesuai dengan fungsinya. Konsep yang akan digunakan dalam perencanaan dan perancangan bangunan Technopark industri furniture meubel yaitu arsitektur tropis. Konsep arsitektur tropis merupakan arsitektur yang merespon iklim tropis sesuai dengan iklim di Indonesia serta menampilkan kesan lokalitas material dari suatu daerah tersebut. Tropis dalam konteks arsitektur memiliki tujuan menyelesaikan permasalahan pada bangunan seperti pemanfaatan pencahayaan alami,penghawaan dan 
menciptakan ruang dengan kenyamanan alami sesuai dengan fungsi ruang.

\section{DAFTAR PUSTAKA}

Noor Cholis Idham dalam buku (2016) “

Arsitektur Tropis dan Kenyamanan

Thermal".

Ching, Francis D.K. Arsitektur Bentuk,

Ruang, dan Tananan. Jakarta. Penerbit

Erlangga

Georg,L.(1997).Bangunan Tropis.Jakarta:

Erlangga.

Purwanto,L.(2006).Arsitektur Tropis

Dalam Penerapan Desain Arsitektur.

Semarang: Universitas Katolik

Soegijapranata.

WisnuSardjonoSoenarso,2016,Pengemban

gan Science dan Technology Park di Indonesia. Hlm.3.

https://btp.or.id/layanan/sewakantor/2017/ bandung-technopark.

https://www.bappenas.go.id/

http://tropicalarchitecture.blogspot.com/20

11/10/bandung-technopark.

http://suarabaru.id/2019/12/04/gedung-

utama-technopark. 